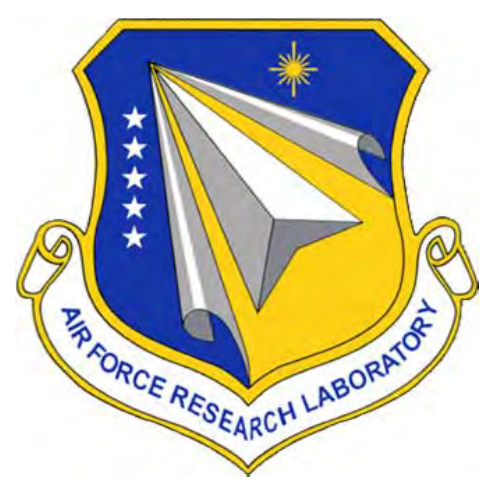

AFRL-AFOSR-UK-TR-2015-0023

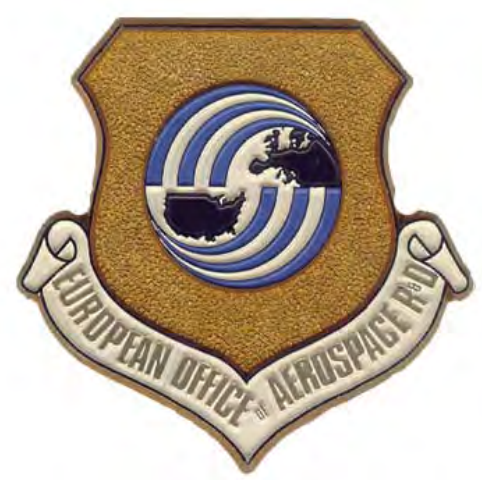

Understanding the unique equatorial density irregularities

Baylie Damtie

Bahir Dar University

Peda Straight, Region 3

Bahir Dar, 79

ETHIOPIA

EOARD GRANT \#FA8655-13-1-3052

Report Date: April 2015

Final Report from 15 June 2013 to 30 March 2015

Distribution Statement A: Approved for public release distribution is unlimited.

\author{
Air Force Research Laboratory \\ Air Force Office of Scientific Research \\ European Office of Aerospace Research and Development \\ Unit 4515, APO AE 09421-4515
}




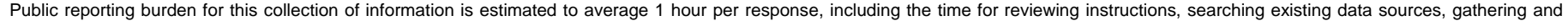

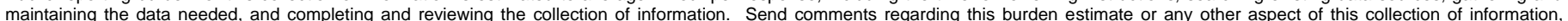

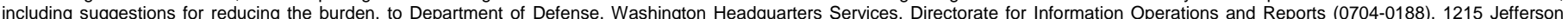

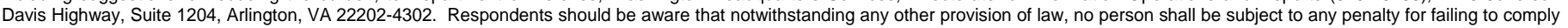
with a collection of information if it does not display a currently valid OMB control number.

PLEASE DO NOT RETURN YOUR FORM TO THE ABOVE ADDRESS.
1. REPORT DATE (DD-MM-YYYY)
2. REPORT TYPE
01 April 2015
Final Report
3. DATES COVERED (From - To)
15 June 2013 - 30 March 2015

\section{TITLE AND SUBTITLE}

Understanding the unique equatorial density irregularities

5a. CONTRACT NUMBER

5b. GRANT NUMBER

FA8655-13-1-3052

5c. PROGRAM ELEMENT NUMBER

$61102 \mathrm{~F}$

6. AUTHOR(S)

Baylie Damtie

5d. PROJECT NUMBER

5d. TASK NUMBER

5e. WORK UNIT NUMBER

\begin{tabular}{l|l}
\hline 7. PERFORMING ORGANIZATION NAME(S) AND ADDRESS(ES) & 8. PERFORMING ORGANIZATION \\
Bahir Dar University & \\
Peda Straight, Region 3 & \\
Bahir Dar, 79 ETHIOPIA & N/A
\end{tabular}

9. SPONSORING/MONITORING AGENCY NAME(S) AND ADDRESS(ES)

10. SPONSOR/MONITOR'S ACRONYM(S)

EOARD

Unit 4515

APO AE 09421-4515

AFRL/AFOSR/IOE (EOARD)

11. SPONSOR/MONITOR'S REPORT NUMBER(S)

AFRL-AFOSR-UK-TR-2015-0023

\section{DISTRIBUTION/AVAILABILITY STATEMENT}

Distribution A: Approved for public release; distribution is unlimited.

\section{SUPPLEMENTARY NOTES}

14. ABSTRACT

The Earth's ionosphere is the well-known threat for applications that depend on trans-ionospheric radio waves. For example, it affects applications like navigation, positioning, and terrestrial communication. The behavior of the ionosphere has been investigated for the past twothree decades all over the globe. However, there are regions, like Africa, that have not been investigated until recently due to lack of groundbased ionospheric monitoring devices. LEO satellite observations in the African sector show unique equatorial ionospheric structure. For example, this region equatorial plasma bubbles, which produce scintillation of radio waves, are much deeper and occur more frequently than bubbles observed in the other region. WaGRL houses different ionospheric monitoring instruments such as SCINDA GPS receiver, Galileo receiver, LEO satellite signal receivers and others in collaboration with institutions outside Ethiopia. This effort provided some support for the installation of the HF Coherent Backscatter Radar (Blue Nile Radar) at Bahir Dar University in collaboration with AFRL in November 2014. Ionospheric empirical models such as NeQuick and IRI have been developed using data collected from ionosondes installed unevenly on the Earth (primarily mid-latitude Northern hemisphere). For realistic ionospheric characteristics estimation for the African ionosphere these models are now using measurements collected locally. The methods developed in this work are also useful for computing three dimensional electron density profiles. Similarly, ionospheric tomography has been applied to reconstruct the ionospheric electron density from GPS receiver measurements. The MATLAB code developed to implement this method is also one of the outputs of this project. These efforts have resulted in six published or submitted publications.

\section{SUBJECT TERMS}

EOARD, ionosphere, equatorial plasma bubbles, Africa

\begin{tabular}{|c|c|c|}
\hline \multicolumn{3}{|l|}{ 16. SECURITY CLASSIFICATION OF: } \\
\hline a. REPORT & b. ABSTRACT & c. THIS PAGE \\
UNCLAS & UNCLAS & UNCLAS \\
\hline
\end{tabular}

17. LIMITATION OF
ABSTRACT
SAR

\begin{tabular}{c|} 
18, NUMBER \\
OF PAGES \\
12
\end{tabular}

19a. NAME OF RESPONSIBLE PERSON
Thomas Caudill

19b. TELEPHONE NUMBER (Include area code) +44 (0)1895616186 


\title{
Understanding the unique equatorial density irregularities
}

\author{
Baylie Damtie \\ Washera Geospace and Radar science Laboratory (WaGRL), Bahir Dar Univer- \\ sity, Ethiopia \\ EOARD Grant: FA8655-13-1-3052 \\ Report Date: March 26, 2015 \\ Final report for the duration from January 1, 2014 to March 30, 2015
}

\section{Introduction}

The Earth's ionosphere is the well known threat for applications that depend on trans-ionospheric radio waves. For example, it affects applications like navigation, positioning, and terrestrial communication. To make a remedial action for the effect of the ionosphere on radio wave, the behavior of the ionosphere has been investigated since two-three decades ago all over the globe. However, there are regions, like Africa, that have not been well investigated until recently due to lack of enough ground-based ionospheric monitoring devices. In addition, the Low Earth Orbiting (LEO) satellites ion density observations show unique features for the African sector [Hei et al. 2005]. To understand the unique characteristics of the African ionosphere different organizations within and outside Africa are being participated. For example, through the IHY-United Nations Basic Space Sciences Initiative (UNBSSI) a number of ground-based ionospheric monitoring devices have been installed in Africa [Amory-Mazaudier, et al. 2009] since 2007. Alongside this activity, universities in Africa (e.g. Bahir Dar University, Ethiopia) have designed space science curriculum for MSc and $\mathrm{PhD}$ level and they are training young scientists in collaboration with universities and research centers found outside Africa (e.g. ICTP, Italy). Washera Geospace and Radar Science Laboratory (WaGRL) at Bahir Dar University, is a good example in collaborating with other institutions (e.g. AFRL, DLR, and Kyoto University) by hosting different ionospheric monitoring instruments and carrying out space science education and research at MSc and $\mathrm{PhD}$ level.

Similarly, funding agencies are supporting the activities being carried out at WaGRL. The EOARD grant FA8655-13-1-3052 is the best example. This final report summarizes accomplishments related to education and ionospheric 
monitoring facilities and research findings that have been obtained in one year research contract ( January 12014 to March 30, 2015) awarded by EOARD. In the coming sections we describe briefly about project objectives and major achievements and research findings that have been obtained in the past one year and three months.

\section{Motivation of the project}

LEO satellite observations, in the African sector, show unique equatorial ionospheric structure [Hei et al. 2005]. For example, this region equatorial plasma bubbles, which produce scintillation of radio waves, are much deeper and occur more frequently than bubbles observed in the other region. However, these observations have not been confirmed, validated or studied in detail from ground due to lack of ground-based instruments in the region, and the question what causes these unique density irregularities in the region is not yet understood. Moreover, global empirical models, which are useful for ionospheric study and related applications, have been developed using ionospheric data mainly collected from the Northern mid-latitude regions. This implies that these models are producing the African ionospheric characteristics by interpolation and it is worthy to investigate answers for the following question: how do the existing models perform in estimating and forecasting the unique ionospheric structures in the African sector? To get answers for these and similar questions (in general to understand and model the African region ionosphere) space science education and research are being carried out at $\mathrm{MSc}$ and $\mathrm{PhD}$ level at Bahir Dar University. In addition to education efforts, new coherent scatter radar, which will be the main data source for equatorial irregularity study, has been installed in collaboration between AFRL and Bahir Dar university. These activities that have been carried out at Bahir Dar University (mainly by PhD students) are useful to complement the efforts that are being carried out, in particular, to understand the unique features of the African equatorial ionosphere and in general to understand the behavior of the ionosphere.

\section{Project achievements and research findings}

\subsection{Coherent Backscatter Radar installation}

WaGRL houses different ionospheric monitoring instruments such as SCINDA GPS receiver, Galelio receiver, LEO satellite signal receivers, VLF, VHF and so on in collaborating with institutions found outside Ethiopia. As a continuation of hosting instruments, HF Coherent Backscatter Radar named Blue Nile Radar is installed at Bahir Dar University in collaboration with AFRL during November 2014. The radar antenna and sample result are shown in Figure 1. Installation of the radar is one of achievements of the project supported by EOARD Grant FA8655-13-1-3052. Data from this system will be analyzed for 
further study to identity the cause for unique feature of the African equatorial ionosphere.

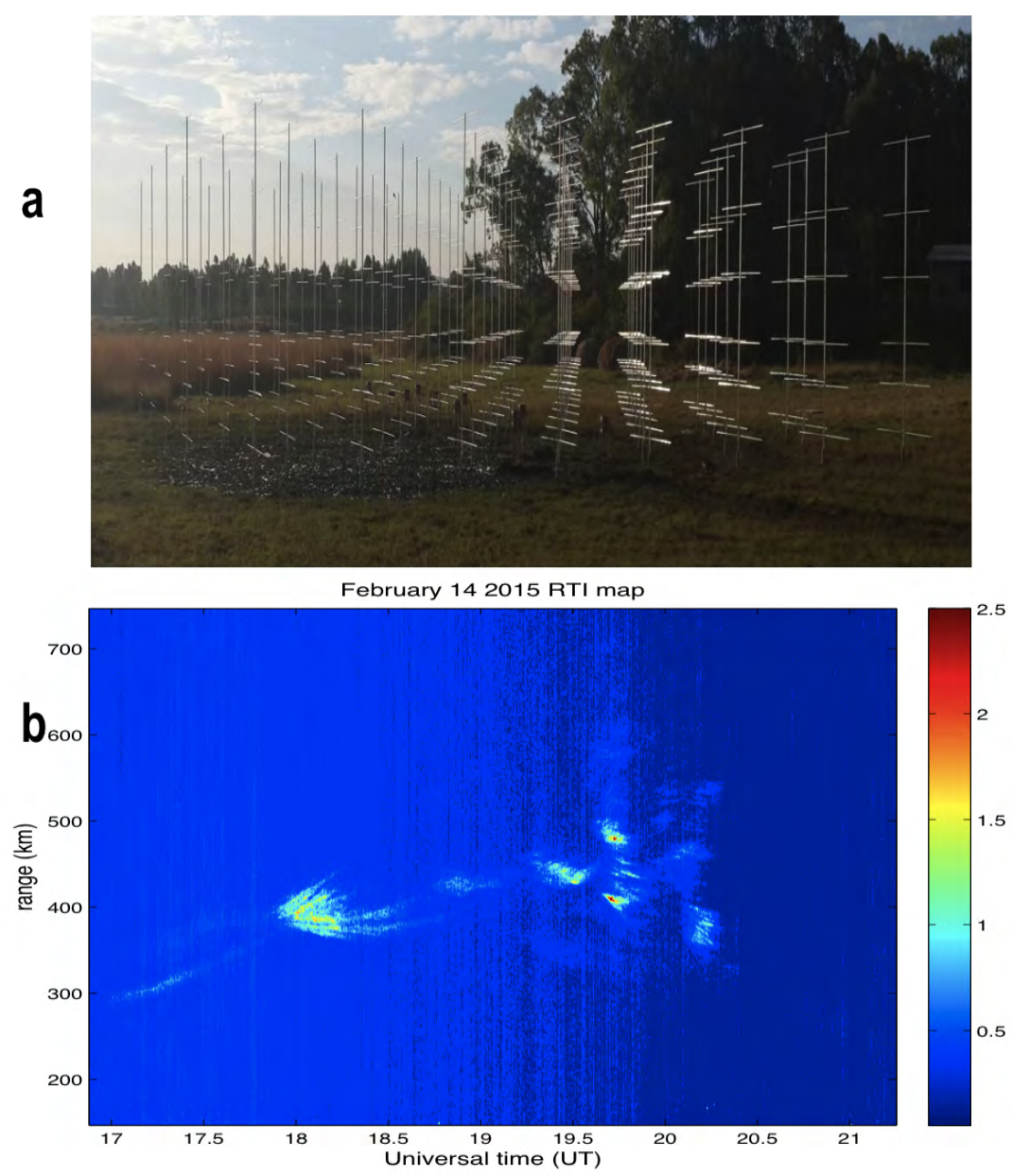

Figure 1: Coherent Backscatter radar antenna (a) and SNR as a function of range and time (b) obtained on 14 February 2015.

\subsection{Education}

Space science education is being carried out at $\mathrm{PhD}$ level at Bahir Dar university to produce experts who will contribute for the understanding of space physics. Supported by EOARD grant FA8655-13-1-3052 six PhD students have been studying space science. In the history of physics department at Bahir Dar university the first PhD student (Melessew Nigussie) in space science (supported 


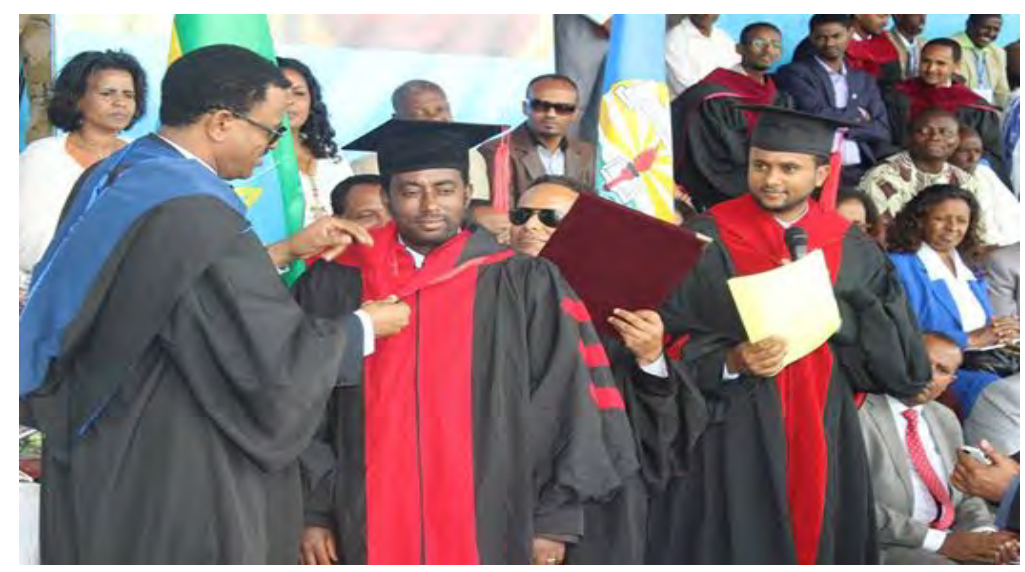

Figure 2: PhD graduation photo.

by TWAS, ICTP in Italy and EOARD grant FA8655-13-1-3052) has obtained his PhD on July 2, 2014 (see graduation photo in Figure 2). His PhD work has been about modeling the East African ionosphere. Dr Melessew has graduated after publishing three papers in well known journals (e.g. AGU, Radio Science).

\subsection{List of publications}

During this project time, we have made significant research findings, which address some of the research questions listed above. The results are found in the papers and manuscripts listed below.

- Nigussie, M., B. Damtie, E. Yizengaw, S. M. Radicella, Modeling the EastAfrican ionosphere, America Geophysical Union (AGU) Book Chapter, in press, 2015.

- Asmare, Y., Kassa, T., Nigussie, M., Validation of IRI-2012 TEC model over Ethiopia during solar minimum (2009) and maximum (2013) phases, Advances in Space Research, 2014.

- Kassa T., Damtie B., Bires A., Yizengaw E., Cilliers P., Storm-time characteristics of the equatorial ionization anomaly in the East African sector, Adv. Space Res., on review.

- Kassa T., Damtie B., Bires A., Yizengaw E., Cilliers P., Spatio-temporal characteristics of the equatorial Ionization Anomaly (EIA) in the East African region via ionospheric tomography during the year 2012, Advances in space research, 55, 184-198, 2015.

- Tesema, F., B. Damtie, M. Nigussie, The response of the ionosphere to intense geomagnetic storms in 2012 using GPS-TEC data from East-Africa 
longitudinal sector, submitted for publication to Atmospheric and SolarTerrestrial Physics journal, it is on review.

- Tebabal A., B. Damtie, A. Bires, M. Nigussie, E. Yizengaw, Reconstruction of total solar irradiance using artificial neural networks, submitted for publication to Atmospheric and Solar-Terrestrial Physics journal, it is on review.

\subsection{Modeling and characterization of the East-African iono- sphere}

Ionospheric empirical models such as NeQuick and IRI have been developed using data collected from ionosonde installed unevenly on the Earth. Most of the data used for these model development have been collected from the mid-latitude of the Northern hemisphere. This implies that these models are being used to estimate ionospheric characteristics for African region by interpolation. So, for realistic ionospheric characteristics estimation for the African

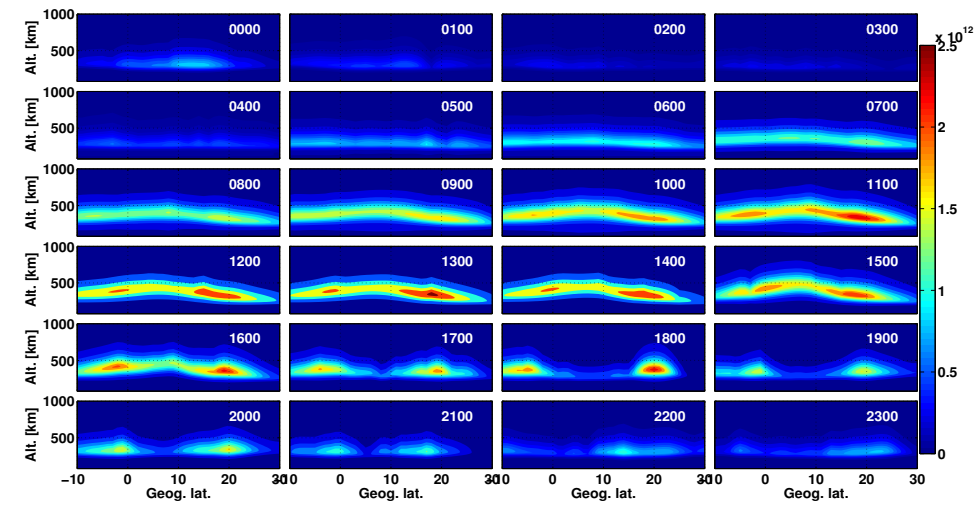

Figure 3: Diurnal variations of the contour plot of electron density profile estimated using NeQuick driven by Az maps at $39^{\circ}$ E on March 11, 2011

ionosphere these models should be assisted by measurements collected recently. For near-real time ionospheric characteristics (electron density and total electron content (TEC)) estimation, new data driven modeling technique, which is used to combine the GPS TEC and the existing empirical model (NeQuick), has been developed. Sample results from this method are shown in Figures 3, 4 , and 5 . Figure 3 shows the diurnal variations of the vertical electron density distribution estimated at $39^{\circ} \mathrm{E}$ meridian. The plots show clear spatiotemporal variation of electron density. Evidently, in the pre-and post-sunset hours (1600 to 2100 UT) symmetric and clear EIA anomalies are depicted unlike that of the results obtained between 1000 and 1500 UT. This indicates that the plasma fountain effect in between 1600 to 2100 UT is much stronger than the plasma 
fountain effect between 1000 to 1500 UT, which could be due to strong prereversal enhancement of $\mathbf{E x B}$ [Fejer et al. 1991].

The methods developed in this work is also useful to compute three dimensional electron density profiles. Figure 4 shows the three-dimensional electron density maps estimated at 1700 UT. This plot shows the latitudinal, longitudinal, and altitude variations of the electron density estimated after model adaptation. As can be seen in this figure while clear latitudinal and altitude variability are visible there is no that much significant longitudinal variation in the electron density distribution, indicating the ionospheric density vary less as a function of longitude.

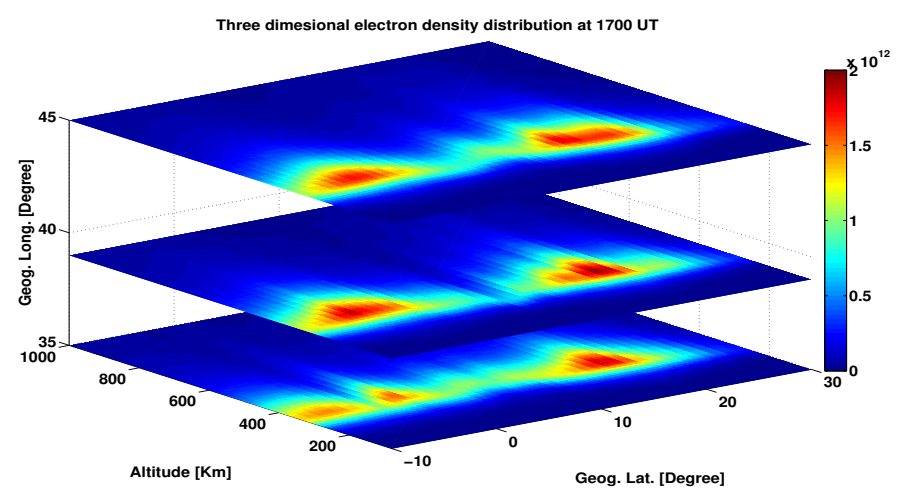

Figure 4: Three dimensional electron density maps estimated by nontomographic technique at 1700 UT on March 11, 2011.

In order to validate the effectiveness of the non-tomographically produced density maps, conjunction $\mathrm{C} / \mathrm{NOFS}$ trajectories have been identified. Figure 5 shows the trajectories of the C/NOFS satellite (top panels) at different local time. The corresponding experimental (from PLP instrument onboard $\mathrm{C} /$ NOFS) and modeled (before (F10.7) and after (Az) data adaptation) electron densities are shown in the bottom panels in Figure 5. As expected the in-situ density estimated after the model adaptation agree very well with the C/NOFS observations, except when the satellite was around F2 peak altitudes $(400 \mathrm{~km})$ as shown in the right bottom panel in Figure 5. This discrepancy might be due to the slight time difference of the ionospheric information utilized for model adaptation (at $1000 \mathrm{UT}$ ) and obtained by the C/NOFS satellite (between 10.0353 and $10.1254 \mathrm{UT}$ ). The method that has been used to produce these results have been published recently in AGU books [Nigussie et al. 2015]. This method will also be applied to investigate different ionospheric phenomena such as the effect of the geomagnetic disturbance on the distribution of the low latitude ionospheric electron density.

Similarly, ionospheric tomography method has been applied, starting from basic principles, to reconstruct the ionospheric electron density from the GPS re- 

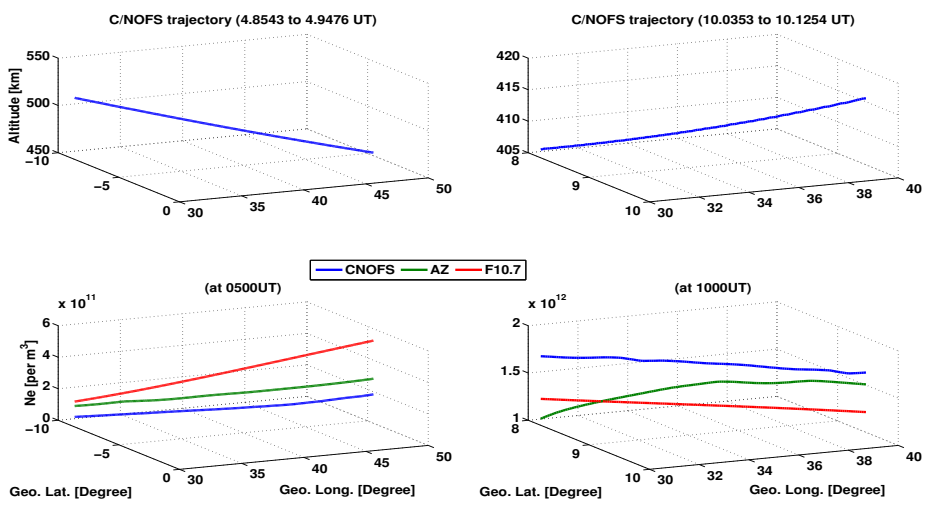

Figure 5: Trajectories of C/NOFS satellite (top panels) and modeled (marked by $\mathrm{Az}$ and $\mathrm{F} 10.7)$ and experimental (C/NOFS) electron densities.

ceiver measurements. The MATLAB code developed to implement this method is one of the outputs of this project. Sample reconstructed electron density maps using this method are shown in Figure 6. The results show the spatiotemporal evolution of the electron density reconstructed from the GPS receiver measurements taken in the East-African ionosphere. This result and other outputs of the method are published [Kassa et al. 2015]. Analysis of data has also been carried out to study the effect of the geomagnetic storm on the equatorial ionosphere. Sample result is shown in Figure 7. This figure shows the spatiotemporal variation of TEC (top two panels) and equatorial electroject (bottom panels) strength (in nT) estimated from magnetometers on 07-11 March 2012. From the study that has been carried out to get this plot, we have found out that the variation of TEC for East-African longitudinal sector mainly affected by the modification of low latitude electrodynamics and neutral composition change due to the storm effect. The work that has been carried out to get this sample result has been submitted for publication to Atmospheric and SolarTerrestrial Physics journal and now it is on review.

The equatorial ionosphere is known on its effect on radio waves. Rapid fluctuation of the ionosphere severely affects a GPS signal. The fluctuation can be described by the scintillation index, which can be estimated from received power of a GPS satellite signal or from the rate of change of total electron content. This means that it is important to have good approach to estimate scintillation index (S4) from the TEC measurements. During this project period, stochastic approach has been applied to estimate the rate of change of TEC (ROTI). Sample output of the method applied is shown in Figure 8. The figure shows the TEC variation, S4 index estimated from SCIND data, and ROTI estimated from TEC using the stochastic approach, from top to bottom, respectively. As can be seen from this result, ROTI from stochastic modeling and S4 index from SCINDA system equivalently describe the fluctuation of the TEC. This 


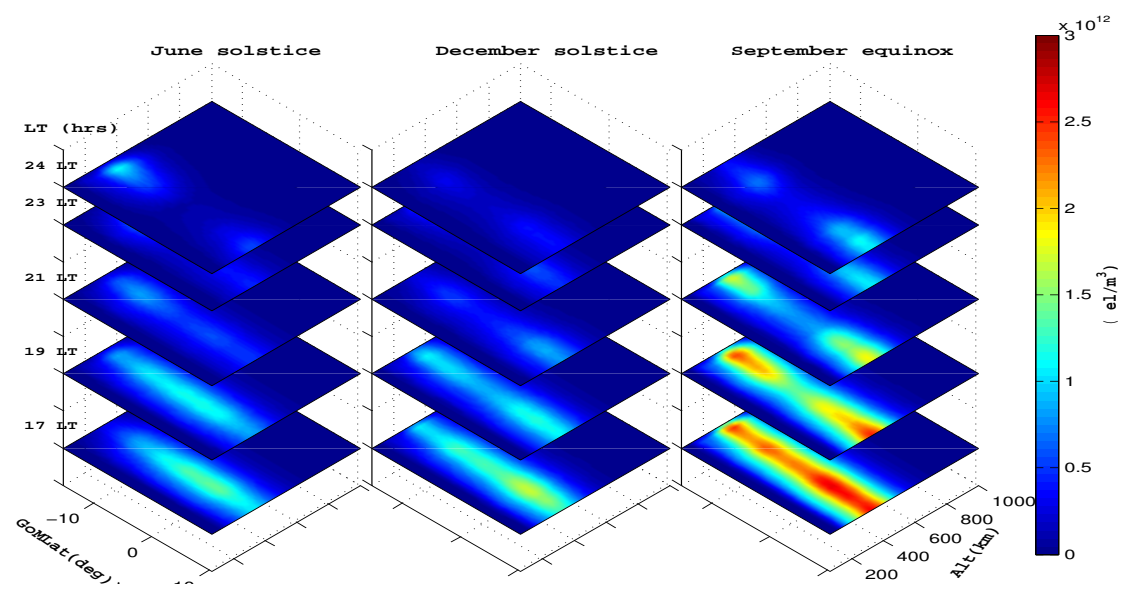

Figure 6: Temporal variations of two dimensional electron density distribution for the East-African ionosphere.

approach is still under development and hence a manuscript will be sent to a journal for publication.

In addition to ionospheric study, we have been involved to model the characteristics of the solar variability, which effects directly the variability of the ionosphere. In this modeling technique we have applied the neural networks package available in MATLAB toolbox, to represent the trend of the data and use it for prediction. Sample results are shown in Figure 9. The results show the comparison of the total solar irradiance (TSI) output from neural networks after data assimilation (green dots) with that of the measurements (black line) that do not involved in assimilation. The comparison shows excellent agreement. This and similar results have been submitted for publication in Atmospheric and Solar-Terrestrial Physics journal and now it is on review.

\section{References}

Amory-Mazaudier, C., S. Basu, O. Bock, A. Combrink, K. groves, T. FullerRowell, P. Lassudrie-Duchesne, M. petitdidier, E. Yizengaw, International Heliophysical Year: GPS Network in Africa, Earth Moon planet, 104, 263-270, doi 10.1007/s11038-008-9273-8, 2009.

Hei, M.A., R. A., Heelis, and J. P. McClure, Seasonal and longitudinal variation of large cale topside equatorial plasma depletions, J. Geophys. Res. 110, A12315, dio:10.1029/2005JA011153, 2005.

Fejer, B. G., E. R. dePaula, S.A. Gonzalez, R. F. Woodman, Average vertical and zonal $\mathrm{F}$ region plasma drifts over Jicamarca, J. geophys. Res., 96(A8),13,901, 1991. 

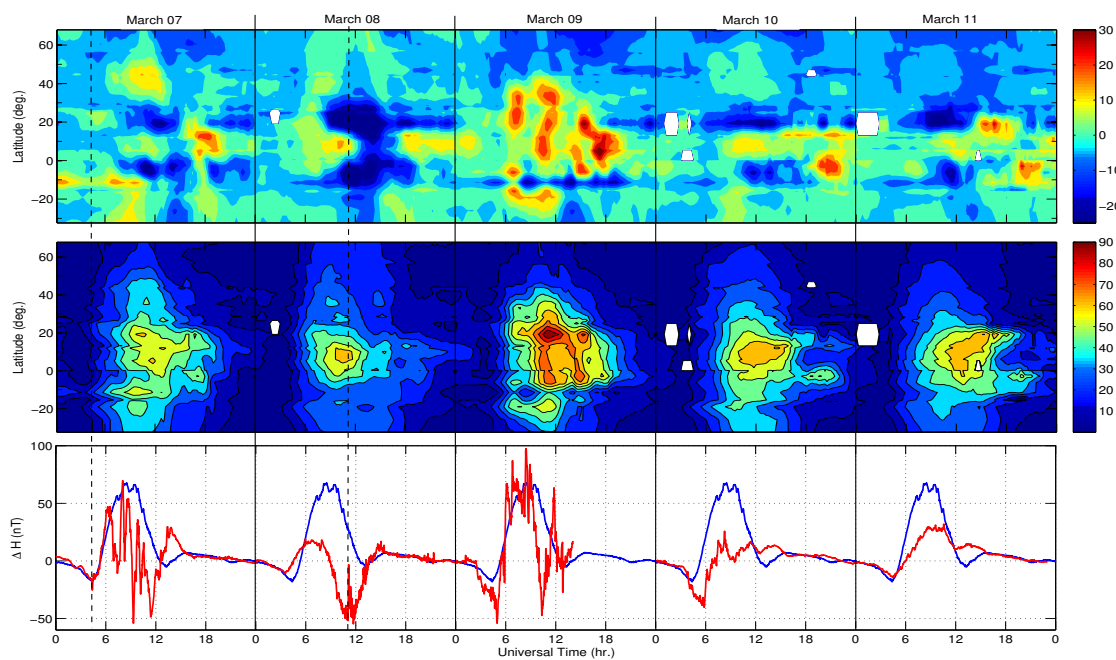

Figure 7: vTEC deviations from quiet day, diurnal vTEC variations and $\Delta \mathrm{H}$ values (red curves) for 07-11 March 2012 from top to bottom respectively. The blue curve on bottom panel shows $\Delta \mathrm{H}$ values on the quietest day of month March 2012. The two vertical broken lines show the SSC time of the storm.

Nigussie, M., B. Damtie, E. Yizengaw, S. M. Radicella, Modeling the EastAfrican ionosphere, America Geophysical Union (AGU) Book Chapter, in press, 2015.

Kassa T., Damtie B., Bires A., Yizengaw E., Cilliers P., Spatio-temporal characteristics of the equatorial Ionization Anomaly (EIA) in the East African region via ionospheric tomography during the year 2012, Advances in space research, 55, 184-198, 2015. 


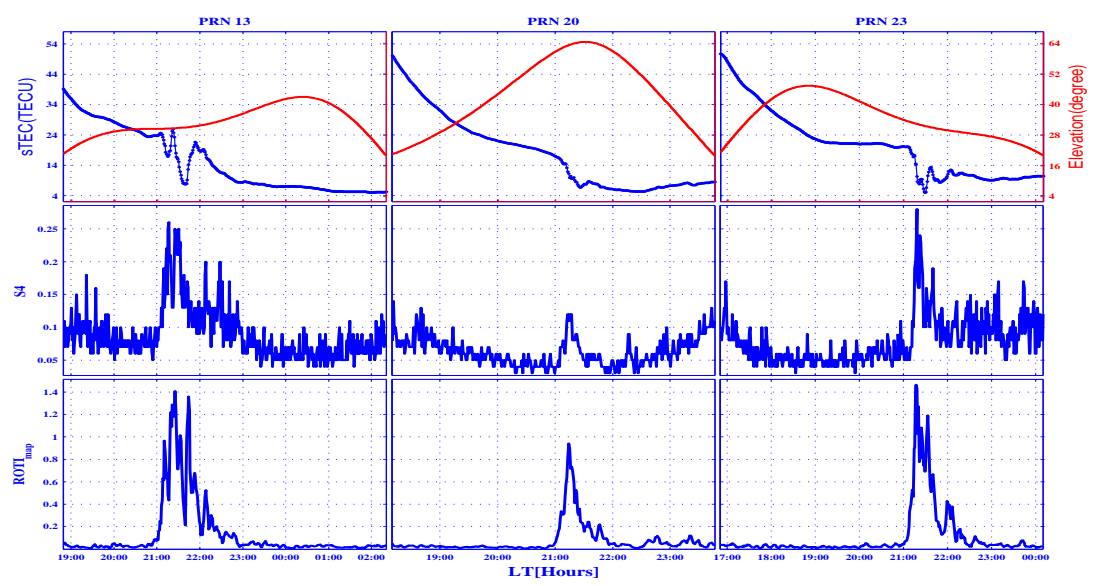

Figure 8: Variation of TEC (top panels), S4 (middle panels), and ROTI (bottom panels).
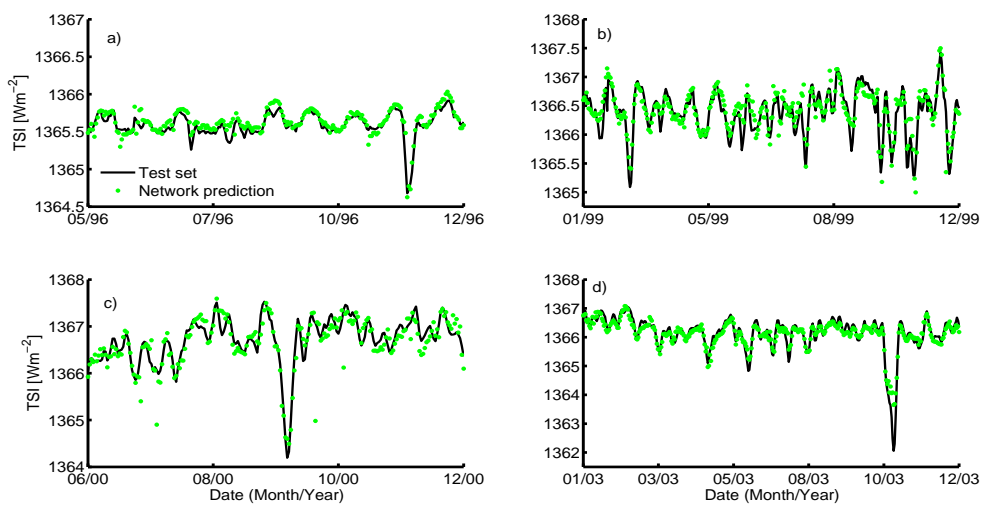

Figure 9: Reconstructed (green) and measured (black line) TSI. 